\title{
Innovative drug delivery nanosystems improve the anti-tumor activity in vitro and in vivo of anti-estrogens in human breast cancer and multiple myeloma
}

\author{
Sébastien Maillard ${ }^{\mathrm{a}}$, Thibault Ameller ${ }^{\mathrm{a}}$, Juliette Gauduchon ${ }^{\mathrm{b}}$, Angélique Gougelet ${ }^{\mathrm{a}}$, \\ Fabrice Gouilleux ${ }^{\mathrm{c}}$, Philippe Legrand ${ }^{\mathrm{a}}$, Véronique Marsaud ${ }^{\mathrm{a}}$, Elias Fattal ${ }^{\mathrm{a}}$, \\ Brigitte Sola ${ }^{\mathrm{b}}$, Jack-Michel Renoir ${ }^{\mathrm{a}, *}$ \\ ${ }^{a}$ UMR CNRS 8612, Pharmacologie Cellulaire et Moléculaire des anticancéreux, 5 rue Jean-Baptiste Clément, 92296 Châtenay-Malabry Cedex, France \\ ${ }^{\mathrm{b}}$ UPRES-EA 2128, Université de Caen, Basse Normandie, Caen, France \\ ' INSERM EMI0351, Université Jules Verne, Amiens, France
}

\begin{abstract}
Anticancer drug efficiency is governed by its bioavailability. In order to increase this parameter, we synthesized several injectable and biodegradable systems based on incorporation of anti-estrogens (AEs) in nanoparticles (NPs) and liposomes were synthesized. Both nanospheres (NS) and nanocapsules (NCs, polymers with an oily core in which AEs were solubilized) incorporated high amounts of 4hydroxy-tamoxifen (4-HT) or RU 58668 (RU). Physico-chemical and biological parameters of these delivery systems, and coupling of polyethylene-glycol chains on the NP surface revealed to enhance the anti-tumoral activity of trapped AEs in a breast cancer MCF-7 cell xenograft model and to induce apoptosis. These features correlated with an augmentation of $\mathrm{p} 21^{\text {Waf- } 1 / \text { Cip1 }}$ and of p27 ${ }^{\text {Kip } 1}$ and a concomitant decrease of cyclin D1 and E in tumor extracts. Liposomes containing various ratios of lipids enhanced the apoptotic activity of RU in several multiple myeloma (MM) cell lines tested by flow cytometry. MM cell lines expressed both estrogen receptor $\alpha$ and $\beta$ subtypes except Karpas 620. Karpas 620 cells which did not respond to AEs became responsive following ER cDNA transfection. A new MM xenograft model was generated after s.c. injection of RPMI 8226 cells in nude mice. RU-loaded liposomes, administered i.v. in this model, at a dose of $12 \mathrm{mg} \mathrm{RU} / \mathrm{kg} /$ week, induced the arrest of tumor growth contrary to free RU or to empty liposomes. Thus, the drug delivery of anti-estrogens enhances their ability to arrest the growth of tumors which express estrogen receptors and are of particular interest for estrogen-dependent breast cancer treatment. In addition it represents a new potent therapeutic approach for multiple myeloma.
\end{abstract}

(C) 2005 Elsevier Ltd. All rights reserved.

Keywords: Drug delivery; Nanoparticles; Liposomes; Anti-estrogens; Cancer cell xenografts

\footnotetext{
Abbreviations: $\mathrm{E}_{2}$, estradiol; ER, estradiol receptor; ERE, estrogen responsive element; MM, multiple myeloma; RU, RU 58668 (11ß-[4-[5-[(4,4,5,5,5pentafluoropentyl)sulfonyl]pentyloxy]phenyl]-estra-1,3,5(10)-triene-3,17ß-diol; 4-HT, 4-hydroxy-tamoxifen; SERM, selective estrogen receptor modulator; SERD, selective estrogen receptor down-regulator; LUC, luciferase reporter gene; DMEM, Dulbecco's modified Eagle's medium; FCS, fetal calf serum; NC, nanocapsules; NP, nanoparticles; NS, nanospheres; PAGE, polyacrylamide gel electrophoresis; PEG, polyethylene-glycol; PLA, poly(D,L lactic acid); SDS, sodium dodecyl sulphate; MTS, 3-(4,5-dimethylthylthiazol-2-yl)-5-(3-carboxymethoxyphenyl)-2-(4-sulfophenyl)-2H-tetrazolium, inner salt; TCE, total cellular extract

is Poster presentation at the 16th International Symposium of the Journal of Steroid Biochemistry and Molecular Biology, 'Recent Advances in Steroid Biochemistry and Molecular Biology' (Seefeld, Tyrol, Austria, 5-8 June 2004).

* Corresponding author. Tel.: +331468358 31; fax: +33146835832.

E-mail address: michel.renoir@cep.u-psud.fr(J.-M. Renoir).
} 


\section{Introduction}

Among estrogen-dependent cancers, breast cancer is certainly the most widespread and the best studied. Worldwide, close to 1 million women per year are diagnosed with breast cancer [1]. For a therapy use, a large number of antiestrogenic molecules have been developed [2] in order to abolish the mitogenic activity of estradiol $\left(\mathrm{E}_{2}\right) . \mathrm{E}_{2}$ exerts its effects in the mammary gland through binding to the estrogen receptors (ER $\alpha$ and $E R \beta)$ belonging to the transcription factor superfamily of nuclear receptors. $E_{2}$ also affects the growth and/or differentiation of other tissues, such as bone, liver, brain and the cardiovascular system [2,3]. The discovery of ER $\beta$ [4] has considerably enhanced our understanding of the mechanism of action of $E_{2}$ and the pharmacology of antiestrogenic molecules (for a review see [5]). As an example, Tamoxifen $\left(\right.$ Novaldex $^{\circledR}$ ), which is the endocrine therapy of choice for the treatment of ER-positive breast cancer, and its active metabolite 4-hydroxy-Tamoxifen (4-HT), display both antagonist/agonist activities which are determined by the nature of the promoter to which ER binds, the nature of the ER ( $\alpha$ or $\beta$ ) predominantly present in the tissue and the cellular content in term of co-activators/co-inhibitors ratio [6]. In fact, Tamoxifen acts as an antagonist in the breast, but behaves as a full agonist in the uterus where it can induce endometrial carcinomas [2]. Thus, Tamoxifen and all the triphenyl ethylene compounds of the same family of molecules, are considered as tissue-selective estrogen receptor modulator (SERM). Unfortunately, Tamoxifen resistance often occurs, and in that case, a blockade of $E_{2}$ synthesis by aromatase inhibitors is sometimes of benefit. In other cases, no response to aromatase inhibitors happens. Thus, despite encouraging improvements in breast cancer treatment, prognosis of metastatic disease is dramatic, stressing the need of new drugs and new administration strategies.

Besides gynecological tumors such as some affecting the ovaries and the uterus, other various tumor pathologies (liver, skin, colon, pancreas, etc.) as well as various nontumor pathologies (benign mastopathies, endometriosis, etc.) have been shown to clinically respond with benefit to antiestrogens [7] but the molecular mechanism(s) of this response is (are) not understood. Multiple myeloma (MM) is still an incurable hemopathy characterized by the clonal accumulation of plasma cells within the bone marrow. For this pathology also, new therapeutic strategies must be envisaged [8]. In previous works, the presence of both ER subtypes in MM cells had been suspected [9-11] and we showed recently that 4HT induces a G1-arrest of cell cycle as well as apoptosis in several MM cells $[12,13]$.

Considering that an orally administration of an antiestrogen (AE) will be widely distributed to the whole body and reach unwanted tissues, we have thought to device injectable and biodegradable, non-toxic formulations loaded with different AEs. In previous studies, we focused on the incorporation of the so-called "pure anti-estrogen" RU 58668 (RU) $[14,15]$ into nanoparticles (NPs) $[15,16]$. RU, like the other AE ICI 182,780 (or Faslodex ${ }^{\circledR}$ or Fulvestran ${ }^{\circledR}$ ), both belong to the class of SERDs (selective estrogen receptor downregulators). Indeed, they induce a fast delocalization and a rapid 26S-proteasome-mediated degradation of ER $\alpha$ in breast cancer cell nucleus [17-19]. NPs were made of a copolymer consisting of a biodegradable poly(D,L-lactic acid) (PLA) covalently bound to a hydrophilic block of polyethylene-glycol (PEG), in order to improve NP stability in blood. This is a prerequisite for obtaining a prolonged circulating time in the blood stream and to increase the probability of NPs to extravasate in tumor tissues. In fact, solid tumors are richly vascularised and their vasculature endothelium is discontinuous [20]. We then choose to use an intravenous administration route of NPs as effective drug carriers able to cross this discontinuous endothelium. When injected in the blood stream, conventional NPs are rapidly opsonized and finally removed from the circulation by the macrophages of the reticuloendothelial system. Covalent coupling of hydrophilic chains at the surface of NPs is a mean to drastically reduce or at least delay, the opsonisation process [20,21]. Two types of NPs were prepared: nanospheres (NS) composed of a polymer matrix in which the anti-estrogen is entrapped, and nanocapsules (NCs) which are vesicular systems in which the active compound is confined to an oily cavity surrounded by a polymer membrane. Nanoparticles loaded with RU or 4-HT were tested in vitro on human cancer cells and in vivo on xenografts bearing human breast cancer cells. Simultaneously, RU was also incorporated in liposomes in order to compare the biological efficiency of both colloidal delivery systems. Finally, RU-loaded liposomes were evaluated on a multiple myeloma (MM) RPMI 8226 xenograft model. In his new MM xenograft model we found that RU-liposomes induce a decrease of the tumor growth.

\section{Materials and methods}

\subsection{Preparation of PEG-coated nanoparticles and PEG-liposomes}

The poly(D,L-lactic acid) polymer $\left(M_{\mathrm{w}}=53 \mathrm{kDa}\right)$ was purchased from Phusis (France). The PEG-PLA NPs were prepared as previously described [16] based on interfacial preformed polymer deposition following solvent displacement. Briefly, $20 \mathrm{mg}$ preformed polymer were solubilized in $1 \mathrm{ml}$ acetone containing various concentrations $\left(2 \times 10^{-5} \mathrm{M}\right.$ to $10^{-3} \mathrm{M}$ ) of RU (Roussel-Uclaf, Romainville, France), then rapidly dispersed into $2 \mathrm{ml}$ of purified water (MilliQ, Millipore ${ }^{\circledR}$ ) following evaporation under nitrogen current. In the case of NCs, only $5 \mathrm{mg}$ preformed polymer per $\mathrm{ml}$ acetone were used but a lipophilic tensioactive agent (Lipoïd S75, Lipoïd GmbH, Ludwigshafen, Germany) and oil (Miglyol 810 , Hüls, Germany) were added to the organic phase.

For liposome preparation we used egg phosphatidylcholine (EPC), a gift from Lipoïd GmbH, 1,2-distearoyl-snglycero-3-phosphoethanol-amine- $N$-methoxy-[poly-(ethyle- 
nglycol)-2000] (DPSE-PEG ${ }^{2000}$ ) and phosphatidylgycerol (Avanti Polar Lipids Inc., Birmingham, USA). Cholesterol (5-cholesten-3 $\beta$-ol) (CHOL) was purchased from Sigma (St. Louis, MO, USA). Liposomes containing $50 \mathrm{mM}$ lipids were prepared by lipidic film hydratation [22] at the following ratios: EPC/DSPE-PEG ${ }^{2000}$ (94:6) or EPC/CHOL/DSPE-PEG ${ }^{2000}$ (64:30:6). RU was loaded into liposomes by mixing with lipids solution. Lipidic film was resuspended in Hepes buffer (Hepes $10 \mathrm{mM} / \mathrm{NaCl} 145 \mathrm{mM}$, $\mathrm{pH}$ 7.0) buffer. The multivesicular preparations were then extruded (extruder Whitley, Lipex, Vancouver, Canada) at room temperature sequentially through 0.2 and $0.1 \mu \mathrm{m}$ polycarbonate membranes. Then, unincorporated RU was eliminated by ultracentrifugation at $300,000 \times g$ for $24 \mathrm{~h}$ at $4{ }^{\circ} \mathrm{C}$ (L8-70, Rotor 50.4 Ti, Beckman, USA).

\subsection{Physicochemical characterization of colloidal systems}

NPs and liposome sizes were measured by Quasi-Elastic Light Scattering (QELS) with a Nanosizer (Coultronics N4Plus, Margency, France). The RU amount incorporated into NPs was measured by a HPLC method at $230 \mathrm{~nm}$ (columm: Hypersil Kromasil C1 (Thermoquest Corp., UK), phase: acetonitrile/phosphate buffer $0.05 \mathrm{M}, \mathrm{pH} 7.0(53 / 47)$ as described previously $[16,23]$. Zeta potential was determined with a Zetasizer 4 Malvern (Malvern Inst., UK). Liposomes samples were diluted in $\mathrm{NaCl} 1 \mathrm{mM}$ solution. $\mathrm{RU}$ incorporated into purified liposomes was determined by UV spectrophotometry at $232 \mathrm{~nm}$ after lipid solubilization in butan-1-ol. Lipid concentration was determined by the enzymatic kit assay PAP 150 (BioMérieux, Lyon, France).

\subsection{Cell culture and transfection}

MCF-7, and MELN [24] cells were cultured in Dulbecco's modified Eagle's medium (DMEM Biological Industries Inc., Kibbutz Beit Haemek, Israel) supplemented with L-glutamine $(2 \mathrm{mM})$, penicillin $(50 \mathrm{IU} / \mathrm{ml})$, streptomycin (50 IU $/ \mathrm{ml}), 10 \%$ fetal calf serum (FCS) and maintained at $37^{\circ} \mathrm{C}$ and $5 \% \mathrm{CO}_{2}$ in humidified atmosphere. MELN cells are MCF-7 cells stably expressing the luciferase (LUC) reporter gene under the control of an estrogen responsive element (ERE) linked to the minimal $\beta$-globulin promoter (ERE$\beta$-globulin-LUC). In the culture conditions described, $0.1 \mathrm{nM}$ $17 \beta$-estradiol $\left(\mathrm{E}_{2}\right)$ was found to induce the maximum LUC transcription in MELN cells. In order to evaluate the release of RU from the formulations, NPs were added for $18 \mathrm{~h}$ in the culture medium or into cell culture inserts, size cut-off: $10 \mathrm{~nm}$ (Nalge Nunc Inc., USA) in the presence or not of $0.1 \mathrm{nM} \mathrm{E}_{2}$. Multiple myeloma cell lines LP-1, OPM-2, NCI-H929, RPMI 8226, U266 and Karpas 620 have been described previously [25]. Cells were maintained in RPMI 1640 medium supplemented with $10 \% \mathrm{FCS}, 100 \mathrm{IU} / \mathrm{ml}$ penicillin, $100 \mu \mathrm{g} / \mathrm{ml}$ streptomycin, $2 \mathrm{mM}$ L-glutamine. Before AE treatment, cells were grown for 3 days in phenol-red free medium supplemented with charcoal-stripped FCS. Transient transfection of Karpas $620 \mathrm{MM}$ cells were performed by electroporation ( $250 \mathrm{~V}, 950 \mu \mathrm{F}$, GenePulser II, Bio-Rad, Marnes la Coquette, France). Cells were washed then seeded at $10^{7}$ cells in $400 \mu \mathrm{l}$ of phenol red/serum-free medium for $2 \mathrm{~h}$ at $37^{\circ} \mathrm{C}$, submitted to electrical field then cultured in complete medium containing charcoal-treated FCS for $48 \mathrm{~h}$. Cells were treated with various concentrations of AEs or vehicle for $24 \mathrm{~h}$ and MTS assays were performed (see below).

\subsection{Cell viability determination (MTS assay)}

Cell viability was assayed using CellTiter 96 Aqueous One Solution ${ }^{\circledR}$ (Promega, Charbonnières, France) following the manufacturer instructions. $10^{4}$ cells were seeded into 96well plates, incubated with vehicle or various concentrations of $\mathrm{AE}$ for various times. Each culture condition was analyzed in triplicate. The values of absorbance at $492 \mathrm{~nm}$ were corrected by subtracting the average absorbance from the control wells containing cell-free medium. Hundred percentage of cell viability was affected to non-treated cells.

\subsection{Cell cycle analysis and apoptosis determination}

For each culture condition, $5 \times 10^{5}$ cells were washed twice in cold phosphate-buffered saline (PBS), pelleted and suspended in ice-cold EtOH (70\% in PBS). Fixed cells were then centrifuged and suspended in PBS containing $100 \mu \mathrm{g} / \mathrm{ml}$ RNase A (Roche Molecular Biochemicals, Meylan, France) and $20 \mu \mathrm{g} / \mathrm{ml}$ propidium iodide (PI, Sigma-Aldrich) for $30 \mathrm{~min}$ at $37^{\circ} \mathrm{C}$. Cells were analyzed with a FACS Calibur (Becton-Dickinson, Le Pont de Claix, France) equipped with an argon laser tuned at $488 \mathrm{~nm}$ and data were obtained with the CellQuest 1.2.2 and the ModFit LT 1.01 softwares (Becton-Dickinson).

\subsection{Western blotting}

Total cell extracts were prepared by addition of lysis buffer (Hepes $50 \mathrm{mM}$ pH $7.5 / \mathrm{NaCl} 150 \mathrm{mM} /$ glycerol $10 \% /$ Triton $\mathrm{X} 1001 \% / \mathrm{MgCl}_{2} 1.5 \mathrm{mM} / \mathrm{EDTA} 1 \mathrm{mM} /$ proteases inhibitors (Complete reagent, Roche Diagnostics, Indianapolis, IN) for $30 \mathrm{~min}$ at $2-4{ }^{\circ} \mathrm{C}$ followed by $10 \mathrm{~min}$ boiling in Laemmli sample buffer. Protein concentration was determined by BioRad Assay modified as in [17] when SDS was present. Proteins were loaded on SDS-PAGE, separated and then electrically transferred onto Immobilon-P membranes (Millipore). Membranes were blocked with $10 \%$ dry non-fat milk and probed with the indicated antibodies overnight at $4{ }^{\circ} \mathrm{C}$. The used antibodies were: a mouse monoclonal antiER $\alpha$ antibody (D12) (sc-8005, Santa-Cruz Biotechnology, Santa-Cruz, CA, USA used at $1 \mu \mathrm{g} / \mathrm{ml}$ ) or a mouse antiER $\beta$ (UCG40) ER- $\beta$ purified rabbit antibody (gift from G. Greene, used at $1 \mu \mathrm{g} / \mathrm{ml}$ ); polyclonal anti-cyclin D1 (Sigma, clone DCS-6, used at 1/200 dilution), anti-p27 Kip-1 (Santa- 
Cruz, used at $1 / 200^{\mathrm{e}}$ dilution), anti-cdk2 (Santa Cruz, used at $1 / 200^{\mathrm{e}}$ dilution), anti-cdk4 (Santa Cruz, used at $1 / 200^{\mathrm{e}}$ dilution), anti-Bax (Euromedex, used at $1 / 1000^{\mathrm{e}}$ dilution), anti-cyclin E (Santa Cruz, used at $1 / 100^{\mathrm{e}}$ dilution) and the anti- $\beta$-actin antibody (sc-1616 Santa-Cruz, used at $1 / 100^{\mathrm{e}}$ dilution antibodies). Membranes were immunoblotted with the corresponding biotinylated (Vectastain ABC kit, Vector Laboratories Inc, Burlingame, CA for ER $\alpha$ ) or horseradish peroxidase (for ER $\beta$ and other antigens) as second antibodies, then exposed after incubation with the enhanced chemiluminescence Western blotting detection reagent (ECL, Amersham Biosciences) to autoradiographic films (X-OMAT-AR, Eastman Kodak Company, Rochester, NY, USA). Signals were normalized by densitometry with reference to $\beta$-actin utilizing the Bio-Profil V99 BIO 1D software from Vilber Lourmat Fisher BioScientific, France).

\subsection{Xenografts experiments}

Sub-confluent MCF-7 cells were resuspended in the culture medium at the density of $5-10 \times 10^{7}$ cells $/ \mathrm{ml}$. Female nude mice (7-8 week-old; Janvier, France) were injected with $200 \mu l$ of this suspension percutaneously as described previously $[14,15]$. Mice injected with MCF-7 cells were then treated weekly with $\mathrm{E}_{2}$ solution in EtOH by skin deposition (100 $\mu \mathrm{g} /$ mouse). The tumors developed during 5-7 weeks reaching $300-500 \mathrm{~mm}^{3}$ (calculated as $1 / 2$ width $\times$ length $^{2}$ ), and then were transplanted (biopsies of $1-2 \mathrm{~mm}^{3}$ ) under the skin in the nipple vicinity of new mice. Tumors were allowed to grow until 5-8 mm diameter (6-8 weeks). All the experiments were carried out with tumor fragments obtained from single tumors for a single group of treated mice.
The test of RU-loaded NPs was performed by i.v. injecting weekly (or biweekly, depending of the experiment) mice bearing $\mathrm{E}_{2}$-dependent MCF-7 cell tumors with various $\mathrm{RU}$ amounts in the presence or not of $E_{2}(0.5 \mathrm{mg} / \mathrm{kg})$.

Sub-confluent RPMI 8226 cells were resuspended in the culture medium at the density of $5-10 \times 10^{7}$ cells $/ \mathrm{ml}$. Female nude mice (7-8 week-old; Janvier, France) were injected with $200 \mu \mathrm{l}$ of this suspension percutaneously as described previously. Tumors developed during 6-8 weeks until 5-8 mm diameter. For mice bearing RPMI 8226 tumors, a single weekly injection of RU-containing liposomes was performed. The tumor volume was measured once a week and at the end of the experiment, the animals were killed and the tumors were removed and weighed. The tumor evolution was calculated as the ratio between the final and the initial tumor weight (week 0). During the experiments, mice had free access to food and water and all the experiments were performed in accordance with the principles of the Declaration of Helsinki and in respect of the French legislation on animal welfare.

\subsection{Statistical analysis}

Student $t$-test was used for the determination of differences between two experiments. Repeated measures ANOVA test was used for comparisons of tumor proliferation curves.

\section{Results}

\subsection{Synthesis of AE-containing colloidal formulations}

In Table 1, we present some of the physico-chemical parameters of both nanospheres (NS) and nanocapsules (NCs)

Table 1

Characteristics of colloidal nanosystems for the drug delivery of anti-oestrogens

\begin{tabular}{|c|c|c|c|c|c|c|}
\hline & RU & $4-\mathrm{HT}$ & $\begin{array}{l}\text { Mean diameter } \\
(\mathrm{nm})\end{array}$ & $\begin{array}{l}\text { Zeta potential } \\
(\mathrm{mV})\end{array}$ & $\begin{array}{l}\text { Encapsulation } \\
\text { efficiency }\end{array}$ & $\begin{array}{l}\text { Encapsulation } \\
\text { percentage } \\
(\%)\end{array}$ \\
\hline \multicolumn{7}{|l|}{ Nanoparticles } \\
\hline PLA NS & - & - & $200 \pm 50$ & $-28 \pm 3$ & $\mathrm{nd}^{\mathrm{a}}$ & nd \\
\hline PLA NS & + & - & $170 \pm 30$ & $-3.1 \pm 0.7$ & $32.8 \mu \mathrm{g} \mathrm{AE} / \mathrm{mg}$ polymer & $\geq 98$ \\
\hline PLA NS & - & + & $172 \pm 33$ & $4.1 \pm 0.6$ & $19 \mu \mathrm{g} \mathrm{AE} / \mathrm{mg}$ polymer & 98 \\
\hline PEG-PLA NS & - & - & $133 \pm 48$ & $-26.1 \pm 0.9$ & nd & nd \\
\hline PEG-PLA NS & + & - & $160 \pm 30$ & $-24.7 \pm 0.6$ & $32.8 \mu \mathrm{g} \mathrm{AE} / \mathrm{mg}$ polymer & 96 \\
\hline PEG-PLA NS & - & + & $137 \pm 47$ & $1.2 \pm 0.7$ & $18.1 \mu \mathrm{g} \mathrm{AE} / \mathrm{mg}$ polymer & 97.6 \\
\hline PLA NC & - & - & $245 \pm 90$ & $-50 \pm 1.1$ & nd & nd \\
\hline PLA NC & + & - & $233 \pm 75$ & $-5.2 \pm 4$ & $5.3 \mu \mathrm{g} \mathrm{AE} / \mathrm{mg}$ polymer & $\geq 99$ \\
\hline PEG-PLA NC & - & - & $233 \pm 67$ & $-44.4 \pm 1.3$ & nd & nd \\
\hline PEG-PLA NC & + & - & $245 \pm 87$ & $-42.2 \pm 2.3$ & $5.3 \mu \mathrm{g} \mathrm{AE} / \mathrm{mg}$ polymer & 98 \\
\hline \multicolumn{7}{|l|}{ Liposomes } \\
\hline EPC/DSPE-PEG $2000(94: 6)$ & - & - & $110 \pm 33$ & $-23.5 \pm 5.8$ & nd & nd \\
\hline EPC/DSPE-PEG ${ }^{2000}(94: 6)$ & + & - & $111 \pm 31$ & $-24.0 \pm 5.8$ & $3.609 \mathrm{mM}$ AE $\times 100 / \mathrm{mM}$ lipids & $\geq 90$ \\
\hline EPC/CHOL/DSPE-2000 (94:30:6) & - & - & $106 \pm 29.7$ & $-25.6 \pm 5.9$ & nd & nd \\
\hline EPC/CHOL/DSPE-PEG ${ }^{2000}$ (64:30:6) & + & - & $94.7 \pm 32.2$ & $-26.5 \pm 5.8$ & $3.205 \mathrm{mM}$ AE $\times 100 / \mathrm{mM}$ lipids & $\geq 90$ \\
\hline
\end{tabular}

The mean diameter and zeta potential (mean values of at least three measures made on three different preparations \pm S.E.M.) of the different formulations containing (+) or not (-) an AE are presented together with the encapsulation efficiency (expressed as the amount of AE encapsulated in $\mu \mathrm{g} / \mathrm{mg}$ polymer for NPs and as $\mathrm{mM} \mathrm{AE} / \mathrm{mM}$ lipid for liposomes, respectively) and the percentage of encapsulation measured as compared to the amount of AE added to the polymers

${ }^{\text {a }}$ Not determined. 
made of PEG-PLA loaded with RU or 4-HT and those of liposomes containing RU. The size of NPs, whatever the $\mathrm{AE}$ incorporated or not, did not vary significantly, contrary to what was observed with other formulations realized in our laboratory, showing a size decrease of pegylated poly(D,L-lactide-co-glycolide) (PEG-PLGA) and of poly( $\varepsilon$ coprolactone) (PEG-PCL) once the hydrophobic RU was incorporated, reflecting compaction of the copolymers as already discussed [16,23]. Moreover the size of liposomes was significantly smaller than that of NPs and was around $110 \mathrm{~nm}$. In the case of 4-HT, the positive zeta potential of NS obtained may indicate that some of the $\mathrm{AE}$ was adsorbed at the polymer surface due to the intrinsic 4-HT charge. On the contrary, RUloaded NPs did not differ in their charge from empty NPs. Since RU has no intrinsic charge, we cannot rule out the presence of some RU at the surface of NPs. The maximum concentration of RU and of 4-HT incorporated in PEG-PLA nanospheres and PEG-PLA nanocapsules reached $5 \times 10^{-4}$ and $2 \times 10^{-5} \mathrm{M}$, respectively.

All liposomes batches were prepared with an initial concentration of RU of $1.25 \mathrm{mM}$ whether cholesterol was added or not in the formulation. RU concentration in liposomes reached $1 \times 10^{-3} \mathrm{M}$, thus at least two times more than the highest amount of RU incorporated in NS. For all formulations, the encapsulation yield was at least $90 \%$. Only the encapsulation rate varied according to the lipidic composition and the uptake efficiency varied with lipids. When cholesterol was added, the uptake efficiency slightly decreased. The mean diameter of all formulations did not exceed $250 \mathrm{~nm}$, a size compatible with a capacity to cross through the discontinuous endothelium at the tumor level [20].

\subsection{Nanosystems retard the AE release}

In order to compare the activity of AEs whether encapsulated or not, we used MELN cells for measuring their anti-estrogenic potential. Fig. 1 reveals that the dosedependent RU-mediated inhibition curve of $\mathrm{E}_{2}$-induced luciferase (LUC) gene transcription in MELN cells was shifted to the right when RU PEG-PLA nanospheres were added in the culture medium. In this experiment, cells were separated from the formulation by the use of inserts in which the NS were introduced. Inserts impeded nanospheres but not free RU to cross the membrane. In MELN cells the maximum LUC activity was obtained at $0.1 \mathrm{nM} \mathrm{E}_{2}$. In the presence of free RU, whether added in the inserts or in the culture medium (the same results were obtained), 50\% inhibition of LUC activity was obtained at $10 \mathrm{nM}$, while the same inhibition extent occurred at a ten fold higher RU concentration when RU was trapped into PEG-PLA NS. This indicates that (a) RU diffuses freely through the insert membrane inhibiting equally LUC expression whether added in the insert or in the culture medium and (b) RU is released slowly from the NS following the degradation of the polymer by the enzymes contained in the serum. Similar experiments performed with liposomes described in Table 1 allowed to conclude that cholesterol in-

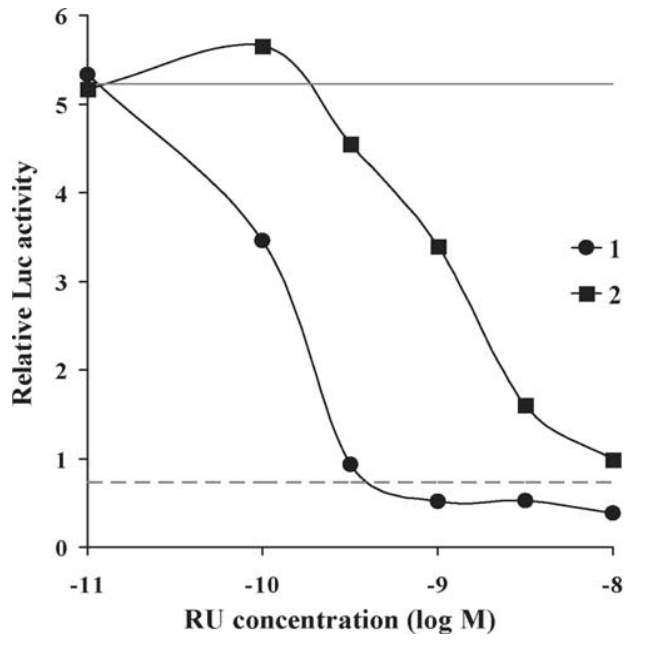

Fig. 1. RU trapped into PEG-PLA nanospheres prolongs its anti-oestrogenic activity. MELN cells (50\% confluence) were grown in phenol red-free DMEM for 3 days then exposed for $18 \mathrm{~h}$ to increasing amounts of free RU introduced into inserts (1) or to RU PEG-PLA nanospheres (same RU concentrations) introduced into inserts (2), in the presence of $0.1 \mathrm{nM} \mathrm{E} 2$ (concentration giving the maximum LUC activity, upper horizontal line). The results (mean of triplicates) are expressed in LUC activity relative to the basal activity level obtained in the absence of $\mathrm{E}_{2}$ (lower discontinuous horizontal line).

corporation in the lipid composition led to slow down RU release from this formulation (not shown).

\subsection{Incorporation of $R U$ in nanosystems enhances the growth inhibition and apoptosis breast cancer cells}

In breast cancer cells, the SERM 4-HT and the SERD RU block cell cycle progression at the G1/S transition phase of cell cycle [26-28]. We compared the response of MCF-7 cells treated with RU or 4-HT, both free or encapsulated into PEG-PLA NS, with that of unloaded NS and NCs (Fig. 2). In addition, RU-loaded NCs were added in the assay. An increase of the amounts of cells in G0/G1 was observed (from $70 \%$ for untreated cells to $80 \%$ at $48 \mathrm{~h}$ and $82 \%$ at $72 \mathrm{~h}$ for RUtreated cells, Fig. 2A). This is consistent with the blockade of MCF-7 cells in quiescence by pure AE [26]. Similar effects were observed with trapped RU in both NS and NCs. By contrast, free 4-HT at the same concentration than RU had no effect on the number of cells in G0/G1 phase at $48 \mathrm{~h}$, but the percentage of cells in G0/G1 increased when 4-HT was entrapped into NS. At $72 \mathrm{~h}$, both free and trapped 4-HT displayed an enhanced effect (Fig. 2A) in agreement with a blockade in $\mathrm{G} 1$ and a potentiation of the anti-proliferative activity of entrapped 4-HT. At both 48 and $72 \mathrm{~h}$, encapsulated 4-HT decreased the $\mathrm{S}$ cell fraction. Concomitantly, while RU $(1 \mu \mathrm{M})$ decreased the $\mathrm{S}$ phase fraction from $20 \%$ to $11 \%$ at both 48 and $72 \mathrm{~h}, \mathrm{RU}$ encapsulated into NS had a similar effect at $48 \mathrm{~h}$ (a decrease from $20 \%$ to $12 \%$ ) but a stronger one at $72 \mathrm{~h}$ (a decrease to $8 \%$ ). RU encapsulated into NCs had a weaker effect (13\% at both times) (Fig. 2B). This may be due to a slower RU release from NCs than from NS in vitro. 


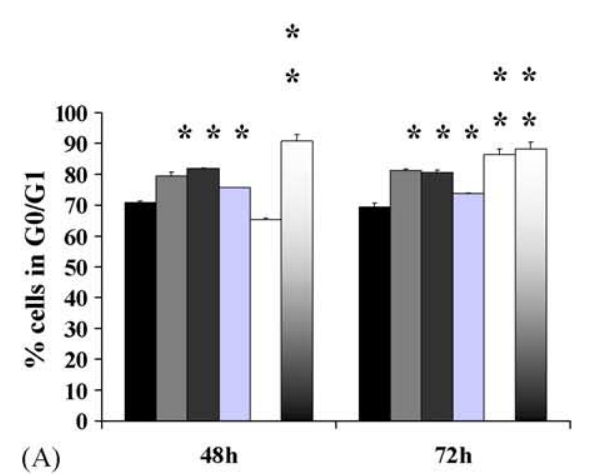

(A)

$48 \mathrm{~h}$

untreated cells (control)

$\square$ free RU 58668

Q RU loaded NS PEG/PLA

$\square$ RU loaded NC PEG/PLA

$\square$ OH-Tam

$\square$ OH-Tam loaded NS PEG/PLA

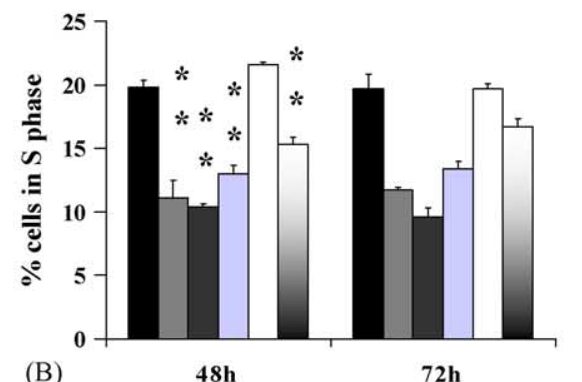

(B)

$48 \mathrm{~h}$

72h

(C)
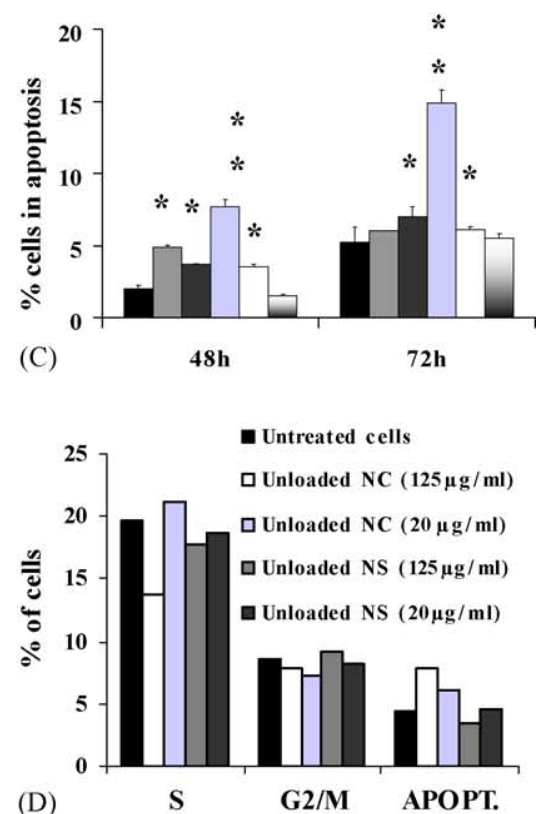

(D)

$\mathrm{S}$

G2/M APOPT.

Fig. 2. Cytofluorometric profiles of MCF-7 cells treated by free and encapsulated 4-HT and RU. MCF-7 cells were treated or not (control, $\square$ ) for 48 or $72 \mathrm{~h}$ with free RU ( $\square, 1 \mu \mathrm{M})$, RU-loaded PEG-PLA NS ( $\square$, RU $1 \mu \mathrm{M}, 20 \mu \mathrm{g} / \mathrm{ml}$ copolymer), RU-loaded PEG-PLA NC ( $\square$, RU $1 \mu \mathrm{M}, 125 \mu \mathrm{g}$ copolymer/ml), free 4-HT $(\square, 4-H T 1 \mu \mathrm{M})$, 4-HT-loaded PEG-PLA NS ( $\square$, 4-HT $1 \mu \mathrm{M}, 20 \mu \mathrm{g}$ copolymer/ml). Cell cycle analysis was performed after PI staining of EtOHpermeabilized cells. The percentage of cells within the G0/G1 phase (A), within the S phase (B) and within the sub-G1 fraction (C) are indicated. In panel D, the percentage of cells within the different phases of the cell cycle were analyzed at the same time and after addition in the culture medium of PEG-PLA NS at $125 \mu \mathrm{g} /$ copolymer $/ \mathrm{ml}$ and of PEG-PLA NC at $20 \mu \mathrm{g}$ copolymer $/ \mathrm{ml}$. Results are the mean values ( \pm S.D.) of triplicates. ${ }^{*} p<0.05$ and ${ }^{* *} p<0.01$ relative to untreated cells.

At the concentration used, RU, whether encapsulated or not, increased time-dependently the population of cells in subG1 (Fig. 2D). This effect is potentiated by incorporation of RU into PEG-PLA NS and much more by encapsulation into NCs. In the same conditions 4-HT, whether free or trapped into PEG-PLA NS, had a weaker potency to induce MCF7 apoptosis than RU at $48 \mathrm{~h}$ but a similar activity at $72 \mathrm{~h}$ (Fig. 2D), indicating a slower time-dependent release of 4HT than of RU from NS. The higher number of cells in subG1 was observed when cells were exposed to RU trapped into NCs (Fig. 2D). However, as shown in Fig. 2D, free NCs induced by themselves a weak increase of the number of cells in sub-G1 which could explain the enhanced apoptotic activity of RU encapsulated into NCs. However, the increase of the number of cells in sub-G1 when exposed to RU- and 4HT-loaded nanoparticles were significantly higher than that of cells exposed to unloaded NC and NS (not shown).

\section{4. $R U$ - and 4-HT-loaded nanoparticles enhance the anti-tumor activity of AEs in MCF-7 xenografts}

Nanospheres of 4-HT and of RU loaded at the same drug concentration were biweekly injected in nude mice bearing MCF-7 cell tumors (see Section 2). As shown in Fig. 3, the increase of the tumor volume of mice having received free 4-HT at $4.3 \mathrm{mg} / \mathrm{kg} /$ week was quite similar to that of the controls. Free RU at the same dose inhibited slightly tumor growth

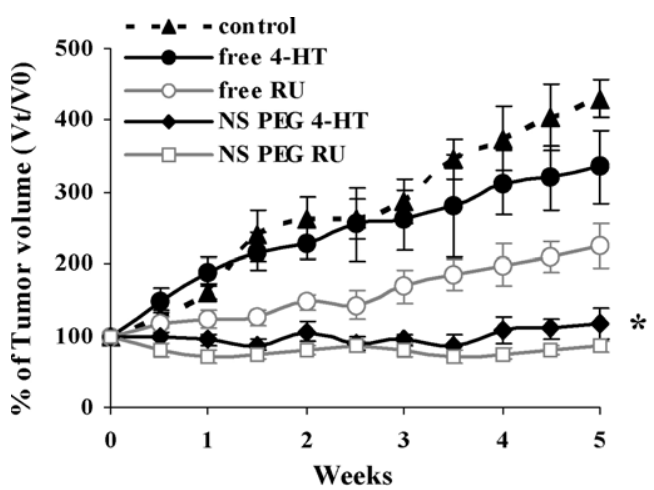

Fig. 3. Antitumoral activity of 4-HT and RU-loaded into PEG-PLA NS in MCF-7 xenografts. Four groups of nude mice $(n=8)$ bearing randomized MCF-7 tumors were biweekly i.v. injected with either free 4-HT $(4.3 \mathrm{mg} / \mathrm{kg} /$ week $)$ in $5 \%$ glucose $(\bullet), 4-H T-l o a d e d ~ P E G-P L A ~ n a n o s p h e r e s$ (4.3 mg 4-HT/kg/week) ( $\downarrow)$, free RU in $5 \%$ glucose $(\bigcirc$; same dose than 4-HT) and RU-loaded PEG-PLA nanospheres ( $\square$; same dose than encapsulated 4-HT), all in the presence of $500 \mu \mathrm{g} \mathrm{E}_{2} / \mathrm{kg} /$ week. The animals of the control group received $E_{2}$ alone $(\boldsymbol{\Lambda})$ at the same dose via the same administration route. Another group ( $\mathbf{\Lambda}$; similar curve) received a biweekly i.v. injection of NCs loaded with RU at $0.25 \mathrm{mg} / \mathrm{kg} / \mathrm{week}$. Twice a week the volume of the tumors was measured. Arbitrary, the volume of the tumors at the beginning of the experiments was fixed to $100 \%$. Results are the mean of calculated tumor volumes \pm S.E.M. ${ }^{*} p<0.05$ relative to RU loaded PEG-PLA NS. RU induces a decrease of the tumor volume while 4-HT reduces their progression rate. 
rate. However, mice which received an identical dose of 4-HT encapsulated in PEG-PLA NS showed a significant inhibition of the tumor growth rate, although less marked than that occurring in xenografts treated with RU-loaded PEG-PLA nanospheres. In this later case, the mean size of the tumors at 5 weeks was significantly lower than that of tumors treated by 4-HT NS and than that of initial untreated tumors, suggesting that formulated RU is able to induce a reduction of the tumor size and not simply to arrest their growth. This is in agreement with previous data obtained with non-formulated free RU injected percutaneously at $250 \mathrm{mg} / \mathrm{kg} /$ week [29]. Here, a decrease of the tumor size after 5 weeks of treatment with RU-loaded NS was achieved for $4.3 \mathrm{mg}$ RU/kg/week. Importantly, NCs loaded with RU at $2 \times 10^{-5} \mathrm{M}$ (thus given at
$1 \mathrm{mg} / \mathrm{kg} /$ week) were not capable of inhibiting the $\mathrm{E}_{2}$-induced tumor growth rate through this administration route (Fig. 3), probably due to insufficient AE amount administered.

\subsection{Cell cycle regulatory proteins in tumors exposed to nanoparticles containing $A E$}

Three to five tumors of similar size from a group of animals equally treated were collected and TCEs were prepared and pooled prior to immunoblotting. The level of each protein was evaluated relatively to $\beta$-actin by densitometric analysis. While cyclin D1 was slightly decreased by free RU and more strongly by RU-loaded NS, it was not affected by free or encapsulated 4-HT (Fig. 4A and B). None of the treatments had
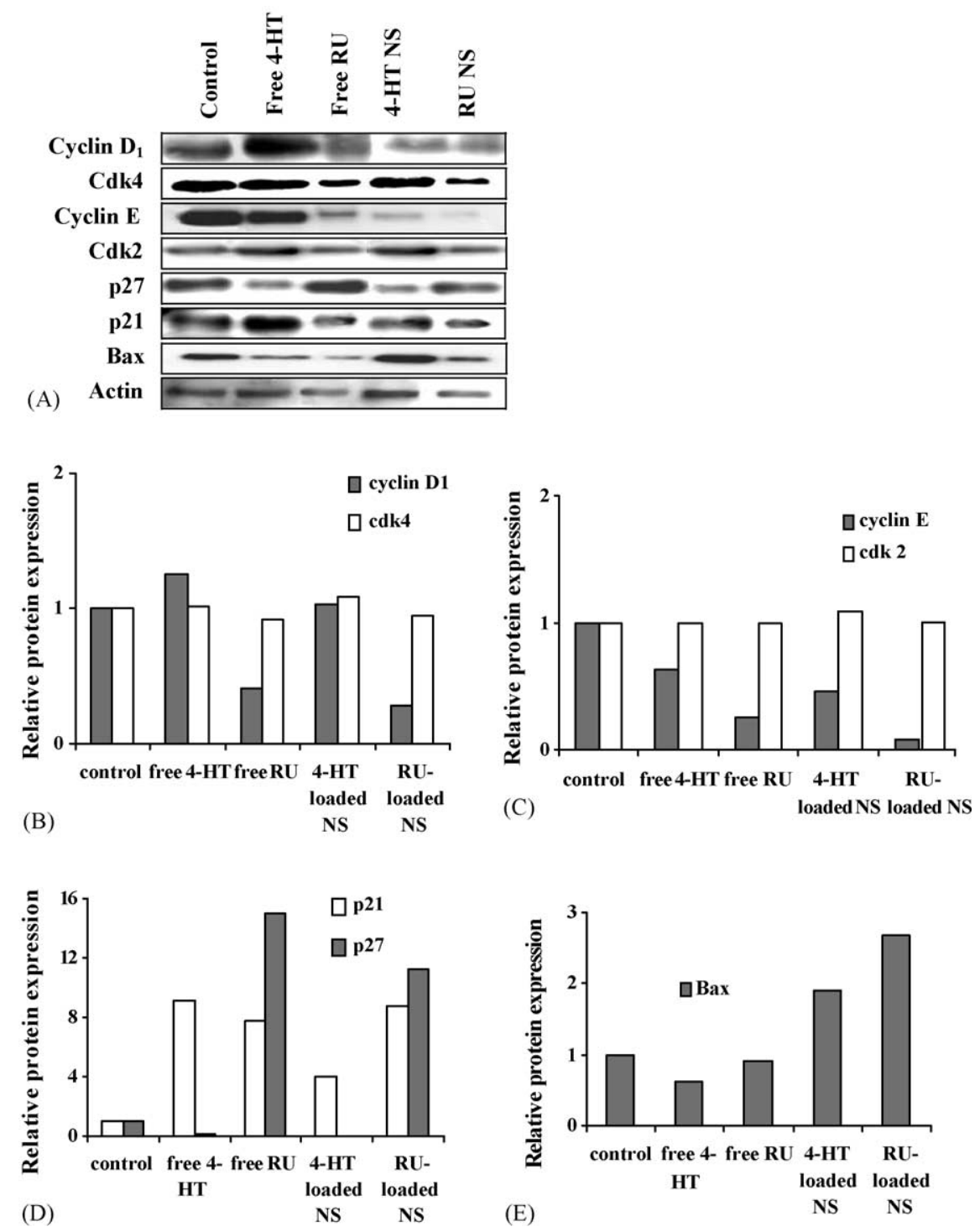

Fig. 4. Expression of cell cycle regulatory proteins in tumors from xenografts treated or not with PEG-PLA NS loaded with either RU or 4-HT. At the end of the experiment described in Fig. 3 tumors were excised homogenized, proteins were extracted as described in Section 2, then $100 \mu \mathrm{g}$ proteins were separated on SDS-PAGE and blotted with the different antibodies (A). Due to the small tumor volume, only $50 \mu \mathrm{g}$ of protein extracts from animal treated with free RU and NS-PEG-PLA RU were analyzed. After blotting with corresponding antibodies, the amount of protein was quantified by scanning densitometry using the Vilber Lourmat software and the relative cyclin D1 and cdk4 expression (B), cyclin E and cdk2 expression (C), p21 Waf1/Cip1 and p27 Kip1 (D) expression were expressed by comparison with the level of actin. In (E), the Bax content is shown similarly. 
an impact on cdk4 level. AE treatments decreased the level of cyclin $E$ with various magnitudes but have no effects on cdk2. The decrease of cyclin $\mathrm{E}$ was more pronounced when AEs were encapsulated (Fig. 4A and C). This is consistent with a blockade of cell cycle progression in cells from tumors exposed to both free or encapsulated 4-HT and RU. More importantly, free as well as encapsulated 4-HT enhanced the $\mathrm{p} 21^{\text {Waf1/Cip1 }}$ levels, while a strong elevation of p27 ${ }^{\mathrm{Kip} 1}$ was noticed upon treatments with both free and encapsulated RU (Fig. 4A and D). This suggests that both AEs are capable of inhibiting cell progression in tumors since these inhibitors can counteract the enzymatic activities of cyclin-cdks complexes. In addition, both presentations enhance the activity of the free drug. Clearly, the signaling pathways used by RU and 4-HT leading to a decrease of the tumor growth are different [27] and are more activated when AEs are encapsulated. One target of the two encapsulated AEs could be the pro-apoptotic Bax which was enhanced by both treatments in tumor extracts, although strongly by RU than by 4-HT (Fig. 4A and $\mathrm{E})$. Increase of $\mathrm{Bax}$ level is well known to conduct numerous cells to apoptosis since this pro-apoptotic agent is essential for mitochondrial-induced cell death [30]. Altogether, these results support the notion that incorporation of RU and 4-HT into nanoparticles increases their anti-tumor activity.

\subsection{Influence of AEs on MM cell proliferation}

MM cells expressed both ER $\alpha$ and ER $\beta$ isotypes except Karpas 620 which was ER negative (Fig. 5). The effect of $\mathrm{AE}$ on MM cells was examined following treatment of the different cell lines with increasing concentrations of either RU or 4-HT. In preliminary experiments using the MTS test (not shown) we found that both AEs did not affect similarly cell proliferation and viability. This was confirmed by further flow cytometry analysis. Results presented in Table 2 indicate that the 4-HT and RU-induced inhibition of MM cell
(A)

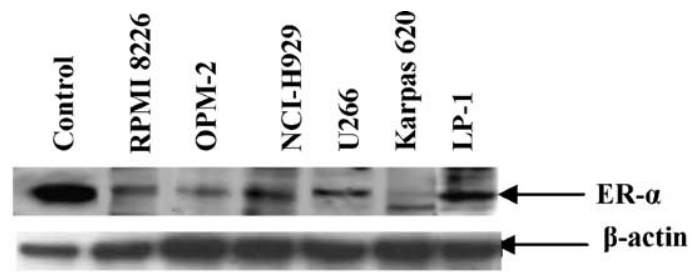

(B)

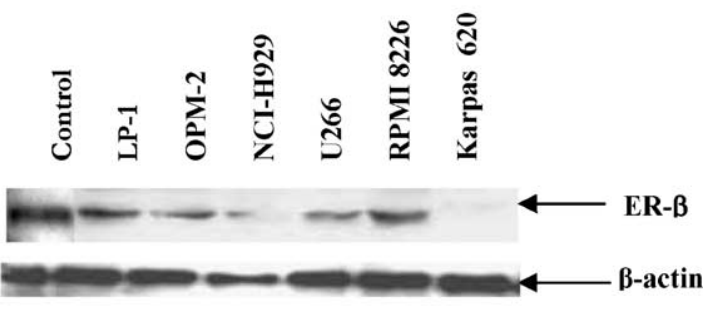

Fig. 5. ER-mediated anti-proliferative response in MM cells. (A) and (B) Western blot analysis of ER- $\alpha$ and ER- $\beta$ in MM cells. Total cell extracts (50 $\mu \mathrm{g}$ protein, A or $100 \mu \mathrm{g}$ protein, B) form the different MM cells were blotted against D12 (A) and E82 (B) antibodies as described in Section 2, in order to visualized ER- $\alpha$ and ER- $\beta$, respectively. $\beta$-actin was assayed as protein loading constant. In control $25 \mu \mathrm{g}$ protein from MCF-7 cell TCEs (A) and $10 \mu \mathrm{g}$ of MDA-MB 231 cells stably transfected with ER- $\beta$ [36] (B) were loaded.

proliferation result from a blockade at G1 except for Karpas 620 cells. Interestingly, both a blockade of cell cycle and an increase of apoptosis were observed with 4-HT, but the two events occurred at different times and at different concentrations according to the cell type. Therefore it could be assumed that they represent independent phenomena. A G1-arrest was observed with RU, in LP-1, OPM-2 and NCI-H929 but not in U266, Karpas 620 and RPMI 8226 cells. Furthermore, in RPMI 8226 cells, RU induced apoptosis (Table 2). In the case of RU, the two phenomena, blockade of the cell cycle and apoptosis increase were never observed concomitantly. However, once incorporated in liposomes, RU induced apop-

Table 2

Cell cycle inhibitory effects and apoptosis capacity of free and entrapped AEs in MM cell lines

\begin{tabular}{|c|c|c|c|}
\hline AE cell lines & 4-HT & RU 58668 & Liposomes RU 58668 \\
\hline LP-1; basal level G0/G1 (38.5\%) & $\begin{array}{l}\mathrm{G} 1 \text {-arrest }(62.5 \% \text { at } 5 \mu \mathrm{M}, \\
48 \mathrm{~h})+ \text { apoptosis }(10 \% \text { at } 10 \mu \mathrm{M} \text {, } \\
48 \mathrm{~h})\end{array}$ & $\begin{array}{l}\mathrm{G} 1 \text {-arrest }(60.4 \% \text { at } \\
5 \mu \mathrm{M}, 48 \mathrm{~h})\end{array}$ & $\begin{array}{l}\text { Apoptosis }(17.6 \% \text { at } \\
1 \mu \mathrm{M}, 48 \mathrm{~h})\end{array}$ \\
\hline OPM-2; basal level G0/G1 (50.8\%) & Unsensitive & $\begin{array}{l}\text { G1-arrest }(60.9 \% \text { at } \\
10 \mu \mathrm{M}, 72 \mathrm{~h})\end{array}$ & $\begin{array}{l}\text { Apoptosis }(21.6 \% \text { at } \\
1 \mu \mathrm{M}, 48 \mathrm{~h})\end{array}$ \\
\hline NCI-H929; basal level G0/G1 (47.3\%) & $\begin{array}{l}\text { G1-arrest }(56 \%)+\text { apoptosis ( } 17 \% \text { at } \\
5 \mu \mathrm{M}, 48 \mathrm{~h})\end{array}$ & $\begin{array}{l}\mathrm{G} 1 \text {-arrest }(65.3 \% \text { at } \\
5 \mu \mathrm{M}, 48 \mathrm{~h})\end{array}$ & $\begin{array}{l}\text { Apoptosis }(22.5 \% \text { at } \\
1 \mu \mathrm{M}, 48 \mathrm{~h})\end{array}$ \\
\hline RPMI 8226; basal level G0/G1 (33.3\%) & $\begin{array}{l}\text { G1-arrest }(74 \%)+\text { apoptosis (13\% at } \\
5 \mu \mathrm{M}, 48 \mathrm{~h})\end{array}$ & $\begin{array}{l}\text { Apoptosis }(26.5 \% \text { at } \\
5 \mu \mathrm{M}, 48 \mathrm{~h})\end{array}$ & $n p^{a}$ \\
\hline U266; basal level G0/G1 (61.5\%) & $\begin{array}{l}\mathrm{G} 1 \text {-arrest }(74 \% \text { at } 5 \mu \mathrm{M}, \\
48 \mathrm{~h})+ \text { apoptosis }(13 \% \text { at } 10 \mu \mathrm{M} \text {, } \\
48 \mathrm{~h})\end{array}$ & Unsensitive & $\begin{array}{l}\text { Apoptosis }(211.9 \% \text { at } \\
1 \mu \mathrm{M}, 48 \mathrm{~h})\end{array}$ \\
\hline Karpas 620; basal level G0/G1 (41\%) & Unsensitive & Unsensitive & $n d^{b}$ \\
\hline
\end{tabular}

Data represent the phases of the cell cycle at which the different MM cell lines were arrested as well as the capacity of the drugs to induce apoptosis in these cells. In parenthesis are indicated the percentages of cells in the phase of the cell cycle considered as well as the concentrations and the times at which each treatment was active. Comparison with the percentage of cells in G0/G1 (basal level) can be made. For each untreated cell line the percentage of cells in apoptosis was $1 \%$ at maximum.

${ }^{\text {a }}$ Not performed.

b Not determined. 


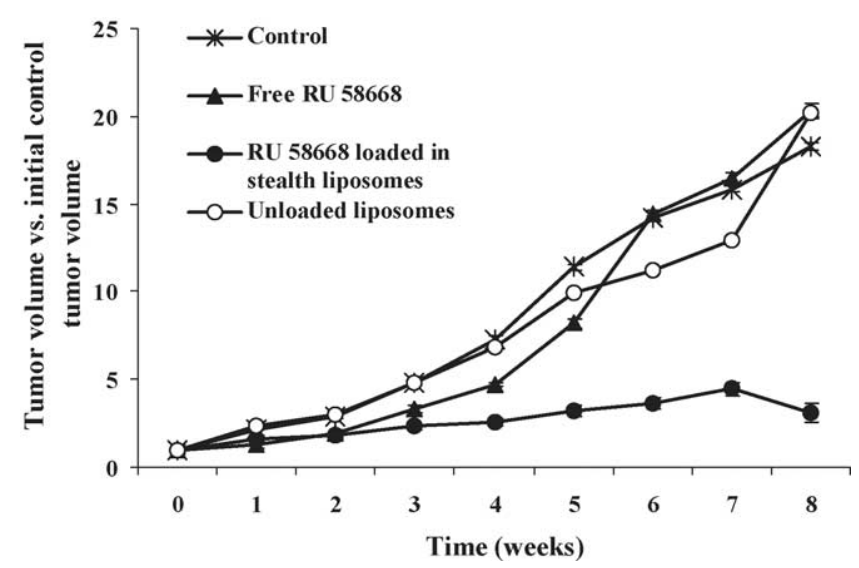

Fig. 6. Tumoral evolution in RPMI 8226-xenografted mice. Mice bearing subcutaneous RPMI 8226 MM tumors, received a weekly injection of either RU-loaded liposomes (12 mg/kg/week of RU) (O), or free RU ( $\mathbf{\Delta})$ $(12 \mathrm{mg} / \mathrm{kg} /$ week), or unloaded liposomes at the same lipid concentration than that containing RU $(\bigcirc)$ or no injection $(\times)$. Each group contains 12-14 mice. Results are the mean value $( \pm$ S.E.M.). Repeated measures ANOVA test showed no significant difference between the control and the free RU group and a significant difference $(p<0.05)$ between the control group and RU-loaded liposome group.

tosis in MM cells at a concentration at which free RU did not induce cell death. This suggests that both 4-HT and RU affect MM cell growth through different signalling pathways and that incorporation of RU in liposomes enhances the $\mathrm{AE}$ activity.

\subsection{Anti-tumor activity of $R U$-loaded liposomes}

Preliminary attempts for obtaining tumors in nude mice after s.c. injection of MM cells lead to get solid tumors at the injection site with only RPMI 8226 cells. We further verified that the tumors obtained presented the same phenotype that RPMI 8226 parental cells. In good correlation with the initial immunology of RPMI 8226 cells, tumoral cells were CD38+, CD138+, CD56-, and smк-/ $\lambda$-. The capacity of RU encapsulated in stealth liposomes to inhibit the growth of RPMItumors was evaluated in this xenograft model. Mice were injected weekly with stealth liposomes (12 mg RU/kg/week) or with free RU at the same concentration in $5 \%$ glucose plus $10 \% \mathrm{EtOH}$. The volumes of tumors were evaluated each week. Eight weeks after the initial injection, tumor volumes of the control group were 20 times higher than that of the initial tumors (Fig. 6). Similarly, the group of animals treated with free RU and the group treated with empty liposomes showed similar enlargement of primary tumors. By contrast, the sizes of tumors in mice treated by RU contained in stealth liposomes increased not more than four times (Fig. 6).

\section{Discussion}

AEs are well known to block the effects of estrogens in both normal and cancerous mammal cells and tamoxifen is used since more than 25 years with success to treat human breast cancer cells in post-menopausal women with ERpositive tumors. New steroidal AEs such as Faslodex ${ }^{\circledR}$ and RU 58668 can suppress the tamoxifen resistance which occurs in some cases; this type of AE has been classified as "pure anti-estrogens" since they are believed to act always as transcriptional antagonists of genes induced by $E_{2}$ at EREcontaining sites in their promoters.

Nevertheless, these AEs need to be reclassified in a group of steroid estradiol receptor down-regulator (SERD) because they are definitely inducers of a rapid proteasomal-mediated destruction of ER $\alpha$ [17-19], inhibiting strongly $E_{2}$-induced transcription. In addition, SERDs like RU and Faslodex ${ }^{\circledR}$ act as agonists when they bind to ER $\beta$ and increase transcription at AP1 sites [31], rendering inappropriate the general term "pure anti-estrogen". In breast cancers, ER $\alpha$ is the major isotype, and RU can be consider as a potent strong anticancer compound for this pathology since it was shown as a strong $\mathrm{E}_{2}$ antagonist in $\mathrm{ER} \alpha$ positive breast cancer cells [27,28]. Unfortunately, RU has not been developed so far but fundamental research works have established its strong potency to inhibit breast cancer cell progression in xenografts models $[14,15]$. Recently, we developed a non-toxic, biodegradable form to deliver i.v. RU in vivo $[15,16]$ and we show here that such a formulation is convenient also for 4-HT [32]. Surprisingly, the PEG-PLA NS loaded with RU and 4-HT are also very efficient to inhibit MCF-7 tumor progression in xenografts following their s.c. injection [32]. In such a model, the mechanisms of action of both AEs, although they used different pathways which are still not completely elucidated, are ER-mediated.

In MM cells, we [12,13] and others [9-11] have detected the presence of ERs in MM cells. However, the expression level of each ER subtype in these cells is at least 20 times weaker than in MCF-7 cells (as measured by semiquantitative Western blot experiments). Other analyses have shown that the growth of none of the MM cells used in our study are $\mathrm{E}_{2}$-independent (J. Gauduchon and B. Sola, data not shown) but 4-HT and RU used affect, although at different extent and at various amounts according to the cell type, cell proliferation or viability. Table 2 indicates that AEs block cell cycle progression and induce apoptosis, but only in MM cells expressing functional ERs. The most striking observation is probably the enhancement of the anti-tumor activity of RUloaded stealth liposomes in the RPMI 8226 xenograft model although unloaded liposomes at same lipid amount did not modify MM cells response. This is explained by prolonged half-live circulation in vivo, as already observed by others $[33,34]$ inducing an accumulation of the formulation and then of RU at the tumor level. In another work [13] we found that 4-HT-induced cell cycle arrest in MM cells is accompanied by an up-regulation of p2 $7^{\mathrm{Kip} 1}$ and a mitochondrial-dependent apoptosis process.

The main question arising from these observations relates to the pathway by which AEs exert their effects in MM cells via ERs. Since these effects occur at high AE concentration 
$(\geq 1 \mu \mathrm{M})$ and since $E_{2}$ has no effect at the same concentration, the classical genomic mechanism [5] of ERs acting as transcription factors is hard to be suspected. Whether a nongenomic activity of AEs in MM cells exists remains to be established. This is not the case for MCF-7 cell xenografts where the up-regulation of both cdk inhibitors $\mathrm{p} 21^{\text {Waf } 1 / C i p 1}$ and $\mathrm{p} 27^{\mathrm{Kip} 1}$ as well as that of Bax could argue for an induced apoptotic activity of RU (confirmed by recent TUNEL experiments, not shown) while the simple augmentation of $\mathrm{p} 21^{\text {Waf } 1 / C i p 1}$ in the case of 4-HT trapped in PEG-PLA NS could corroborate with an arrest of the cell cycle progression. Nevertheless, the results obtained with the different drug delivery systems we have developed strongly, indicate that they constitute a potent new therapeutic strategy for anti-estrogen administration not only for estrogen-dependent pathologies such as breast cancer but also for other diseases in which estrogen receptors (and/or other signaling molecules) are targeted by anti-estrogens. The exact molecular mechanism of the enhancement of anti-estrogen activity following their incorporation into stealth colloidal formulations is still under current investigation. Such a strategy using more toxic drugs like platinum salts (or taxotere) showed recently to be of high clinical interest [35].

\section{Acknowledgements}

We thank P. Van de Velde and G. Greene for the gift of RU 58668 and anti ER $\beta$ antibody, respectively. Plasmids expressing ER $\alpha$ and ER $\beta$ cDNAs were obtained from P. Chambon and B. Haendler, respectively. We thank M. Pons and J.C. Nicolas for the gift of MELN cells and J. Mester and R. Bataille for advices and encouragements. This work was supported by the Ligue Nationale Contre le Cancer (Comité de l'Indre, de la Manche et du Cher), the Fondation pour la Recherche Médicale and the Association pour la Recherche Contre le Cancer (grants 9863 and 5970 to JMR), and the Foundation de France (Grant No. 2002004328 to BS).

\section{References}

[1] R.T. Greenlee, M.B. Hill-Harmon, T. Murray, M. Thun, Cancer statistics, 2001, CA Cancer J. Clin. 51 (2001) 15-36.

[2] J.I. MacGregor, V.C. Jordan, Basic guide to the mechanisms of antiestrogen action, Pharmacol. Rev. 50 (1998) 151-196.

[3] R. Clarke, F. Leonessa, J.N. Welch, T.C. Skaar, Cellular and molecular pharmacology of antiestrogen action and resistance, Pharmacol. Rev. 53 (2001) 25-71.

[4] S. Mosselman, J. Polman, R. Dijkema, ER beta: identification and characterization of a novel human estrogen receptor, FEBS Lett. 392 (1996) 49-53.

[5] S.T. Pearce, V.C. Jordan, The biological role of estrogen receptors alpha and beta in cancer, Crit. Rev. Oncol. Hematol. 50 (2004) 3-22.

[6] D.P. McDonnell, The molecular pharmacology of SERMs, Trends Endocrinol. Metab. 10 (1999) 301-311.

[7] V.C. Jordan, Antiestrogens and selective estrogen receptor modulators as multifunctional medicines. 2. Clinical considerations and new agents, J. Med. Chem. 46 (2003) 1081-1111.
[8] T. Hideshima, P.L. Bergsagel, W.M. Kuehl, K.C. Anderson, Advances in biology of multiple myeloma: clinical applications, Blood (2004).

[9] L. Danel, C. Vincent, F. Rousset, B. Klein, R. Bataille, M. Flacher, B.G. Durie, J.P. Revillard, Estrogen and progesterone receptors in some human myeloma cell lines and murine hybridomas, J. Steroid Biochem. 30 (1988) 363-367.

[10] S.P. Treon, G. Teoh, M. Urashima, A. Ogata, D. Chauhan, I.J. Webb, K.C. Anderson, Anti-estrogens induce apoptosis of multiple myeloma cells, Blood 92 (1998) 1749-1757.

[11] T. Otsuki, O. Yamada, J. Kurebayashi, T. Moriya, H. Sakaguchi, H. Kunisue, K. Yata, M. Uno, Y. Yawata, A. Ueki, Estrogen receptors in human myeloma cells, Cancer Res. 60 (2001) 1434 1441.

[12] J. Gauduchon, F. Gouilleux, S. Maillard, V. Marsaud, M.J. Renoir, B. Sola, The selective estrogen receptor modulator 4-hydroxy tamoxifen induces G1 arrest and apoptosis of multiple myeloma cell lines, Ann. NY Acad. Sci. 1010 (2003) 321-325.

[13] J. Gauduchon, F. Gouilleux, S. Maillard, V. Marsaud, J.M. Renoir, B. Sola, The 4-hydroxytamoxifen induces a cell cycle arrest through the up-regulation of p27Kip1 and a mitochondrial-dependent apoptosis in human myeloma cells, submitted for publication.

[14] P. Van de Velde, F. Nique, F. Bouchoux, J. Bremaud, M.C. Hameau, D. Lucas, C. Moratille, S. Viet, D. Philibert, G. Teutsch, RU 58,668, a new pure antiestrogen inducing a regression of human mammary carcinoma implanted in nude mice, J. Steroid Biochem. Mol. Biol. 48 (1994) 187-196.

[15] T. Ameller, V. Marsaud, P. Legrand, R. Gref, J.M. Renoir, In vitro and in vivo biologic evaluation of long-circulating biodegradable drug carriers loaded with the pure antiestrogen RU 58668, Int. J. Cancer 106 (2003) 446-454.

[16] T. Ameller, V. Marsaud, P. Legrand, R. Gref, G. Barratt, J.M. Renoir, Polyester-poly(ethylene glycol) nanoparticles loaded with the pure antiestrogen RU 58668: physicochemical and opsonization properties, Pharm. Res. 20 (2003) 1063-1070

[17] V. Marsaud, A. Gougelet, S. Maillard, J.M. Renoir, Various phosphorylation pathways, depending on agonist and antagonist binding to endogenous estrogen receptor alpha (ERalpha), differentially affect ERalpha extractability, proteasome-mediated stability, and transcriptional activity in human breast cancer cells, Mol. Endocrinol. 17 (2003) 2013-2027.

[18] A.L. Wijayaratne, D.P. McDonnell, The human estrogen receptoralpha is a ubiquitinated protein whose stability is affected differentially by agonists, antagonists, and selective estrogen receptor modulators, J. Biol. Chem. 276 (2001) 35684-35692.

[19] D.L. Stenoien, K. Patel, M.G. Mancini, M. Dutertre, C.L. Smith, B.W. O'Malley, M.A. Mancini, FRAP reveals that mobility of oestrogen receptor-alpha is ligand- and proteasome-dependent, Nat. Cell Biol. 3 (2001) 15-23.

[20] A. Gabizon, D. Papahadjopoulos, Liposome formulations with prolonged circulation time in blood and enhanced uptake by tumors, Proc. Natl. Acad. Sci. U.S.A. 85 (1988) 6949-6953.

[21] K.S. Soppimath, T.M. Aminabhavi, A.R. Kulkarni, W.E. Rudzinski, Biodegradable polymeric nanoparticles as drug delivery devices, J. Control. Release 70 (2001) 1-20.

[22] A.D. Bangham, M.M. Standish, J.C. Watkins, Diffusion of univalent ions across the lamellae of swollen phospholipids, J. Mol. Biol. 13 (1965) 238-252.

[23] T. Ameller, V. Marsaud, P. Legrand, R. Gref, J.M. Renoir, Pure antiestrogen RU 58668-loaded nanospheres: morphology, cell activity and toxicity studies, Eur. J. Pharm. Sci. 21 (2004) 361-370.

[24] M. Pons, D. Gagne, J.C. Nicolas, M. Mehtali, A new cellular model of response to estrogens: a bioluminescent test to characterize (anti) estrogen molecules, Biotechniques 9 (1990) 450-459.

[25] X. Troussard, H. Avet-Loiseau, M. Macro, M.P. Mellerin, M. Malet, M. Roussel, B. Sola, Cyclin D1 expression in patients with multiple myeloma, Hematol. J. 1 (2000) 181-185. 
[26] J.S. Carroll, O.W. Prall, E.A. Musgrove, R.L. Sutherland, A pure estrogen antagonist inhibits cyclin E-Cdk2 activity in MCF-7 breast cancer cells and induces accumulation of p130-E2F4 complexes characteristic of quiescence, J. Biol. Chem. 275 (2000) 38221-38229.

[27] J.S. Carroll, D.K. Lynch, A. Swarbrick, J.M. Renoir, B. Sarcevic, R.J. Daly, E.A. Musgrove, R.L. Sutherland, p27(Kip1) induces quiescence and growth factor insensitivity in tamoxifen-treated breast cancer cells, Cancer Res. 63 (2003) 4322-4326.

[28] S. Somai, M. Chaouat, D. Jacob, J.Y. Perrot, W. Rostene, P. Forgez, A. Gompel, Antiestrogens are pro-apoptotic in normal human breast epithelial cells, Int. J. Cancer 105 (2003) 607-612.

[29] P. Van de Velde, F. Nique, J. Bremaud, M.C. Hameau, D. Philibert, G. Teutsch, Exploration of the therapeutic potential of the antiestrogen RU 58668 in breast cancer treatment, Ann. NY Acad. Sci. 761 (1995) 164-175.

[30] D.D. Newmeyer, S. Ferguson-Miller, Mitochondria: releasing power for life and unleashing the machineries of death, Cell 112 (2003) 481-490.

[31] K. Paech, P. Webb, G.G. Kuiper, S. Nilsson, J. Gustafsson, P.J. Kushner, T.S. Scanlan, Differential ligand activation of estrogen receptors ERalpha and ERbeta at AP1 sites, Science 277 (1997) 1508-1510.
[32] T. Ameller, A. Gougelet, D. Challuau, P. Ardouin, E. Connault, P. Opolon, P. Legrand, V. Marsaud, J.M. Renoir, Improved antiproliferative efficiency of long-circulating RU 58668-vs 4-OHtamoxifen-loaded nanoparticles in MCF-7 cell xenografts accompanies increased expression of $\mathrm{p} 21^{\text {Waf1/Cip } 1}$ and $\mathrm{p} 27^{\mathrm{Kip} 1}$ and apoptosis induction, submitted for publication.

[33] T.M. Allen, C. Hansen, F. Martin, C. Redemann, A. Yau-Young, Liposomes containing synthetic lipid derivatives of poly(ethylene glycol) show prolonged circulation half-lives in vivo, Biochim. Biophys. Acta 1066 (1991) 29-36.

[34] D.C. Drummond, O. Meyer, K. Hong, D.B. Kirpotin, D. Papahadjopoulos, Optimizing liposomes for delivery of chemotherapeutic agents to solid tumors, Pharmacol. Rev. 51 (1999) 691743.

[35] K.N. Burger, R.W. Staffhorst, H.C. de Vijlder, M.J. Velinova, P.H. Bomans, P.M. Frederik, B. de Kruijff, Nanocapsules: lipid-coated aggregates of cisplatin with high cytotoxicity, Nat. Med. 8 (2002) $81-84$.

[36] S.O. Mueller, J.M. Hall, D.L. Swope, L.C. Pedersen, K.S. Korach, Molecular determinants of the stereoselectivity of agonist activity of estrogen receptors (ER) alpha and beta, J. Biol. Chem. 278 (2003) $12255-12262$. 